\title{
Os efeitos da notícia da revolução liberal do Porto na província de Pernambuco e a crise do sistema colonial no nordeste do Brasil (1820 -1821)
}

\author{
Flavio José Gomes Cabral \\ Universidade Federal de Pernambuco, Brasil \\ gomescabral@uol.com.br
}

\begin{abstract}
Resumen
Basado en fuentes primarias provenientes de archivos brasileros y portugueses, el artículo investiga los efectos de la Revolución de Porto (24 de agosto de 1820) en Pernambuco (Brasil) y la existencia de una red de comunicaciones que fue capaz de mantener a las gentes, sobre todo a los sectores populares, al tanto de las novedades. Aunque estaba prohibido hablar de política, los brasileros consiguieron burlas las normas y a escondidas conversaban, cantaban poemas de naturaleza política, publicaban pasquines contra el gobierno, escribían cartas y pintaban los muros. Durante muchos años la historiografía nacional negó la participación de los sectores populares en el proceso de Independencia. El artículo procura mostrar lo contrario. Dada la existencia de una red de comunicación, estos sectores pudieron participar en este proceso político a partir de lo que hablaban, veían y escuchaban en las calles.
\end{abstract}

Palabras clave: BRASIL, PORTUGAL, REVOLUCIÓN DE PORTO, SIGLO XIX.

\section{Resumo}

Ancorado em fontes primárias provenientes de arquivos brasileiros e portugueses o artigo procura investigar os efeitos da Revolução do Porto (24/08/1820) em Pernambuco (Brasil) bem como a existência de uma rede de comunicação que foi capaz deixar as pessoas, principalmente os populares, a par das novidades. Mesmo proibidos de falar em coisas relativas a política conseguiram os brasileiros driblar as normas proibitivas e às escondidas conversavam, cantavam poemas de natureza política, afixavam pasquins contra o governo, escreviam cartas e pichavam os muros driblando dessa maneira as normas proibitivas. Durante muitos anos a historiografia nacional negou a participação de populares no processo de Independência. $\mathrm{O}$ artigo procura mostrar o contrário. Dada a existência de uma teia de comunicação puderam os populares tomar parte naquele processo político uma vez que falavam o que viam e ouviam nas ruas, portanto não se encontravam excluídos, tendo em vista que falavam.

Palavras-chave: BRASIL, PORTUGAL, REVOLUÇÃO DO PORTO, SÉCULO XIX. 


\begin{abstract}
Based on primary sources from Brazilian and Portuguese archives, the article investigates the effects of the Revolution of Porto (August 24 of 1820) in Pernambuco (Brazil) and the existence of a communications network that was able to maintain people, especially the populace, up to date. Although it was prohibited to talk about politics, the Brazilians were able to mock the rules and secretly talked about them, sang poems of political nature, published pamphlets against the government, wrote letters and painted walls. During many years, national historiography denied the participation of the populace in the process of Independence. The article tries to show the opposite. Given the existence of a communications network, these sectors could participate in the political process by speaking about what they saw and listened in the streets.
\end{abstract}

Key words: BRAZIL, PORTUGAL, REVOLUTION OF PORTO, 19th CENTURY.

No dia 22 de outubro de 1820, atracava no porto do Recife, principal vila da província de Pernambuco, o navio inglês Chresterfiel, trazendo as recentes notícias sobre uma revolução iniciada na cidade portuguesa do Porto no dia 24 de agosto, a qual havia dado início a um movimento de caráter constitucionalista que exigia, entre outras medidas, a convocação de cortes, o que de certa forma punha em xeque a monarquia absoluta. As primeiras convocações de cortes se deram em Lamego, em 1143, para estabelecer as leis fundamentais da sucessão portuguesa. Nos primórdios do século XIX, a idéia de convocação de cortes em Portugal era vista como subversiva, motivo de perseguições e prisões até 1808, quando então, estando o país sob o domínio francês, uma simulação de reunião de cortes tem lugar para escolher um soberano. A idéia de convocação dessas assembléias estivera presente nos movimentos lusitanos de 1817 e de 1820 . Neste último, o termo "cortes" passou a ser visto pelos liberais como órgão de representação nacional, adquirindo a denominação "congresso", que foi a primeira instituição parlamentar do liberalismo ${ }^{1}$.

Naquele momento, o governador Luís do Rego Barreto, último governador régio da província, que estava prestes a viajar para o interior da província no intuito de debelar um movimento de camponeses sebastianistas ${ }^{2}$, chefiando in loco as forças

1 Isabel Nobre Vargues y Maria Manuela Tavares Riveiro, "Estruturas políticas: parlamentos, eleições, partidos políticos e maçonarias”, en O liberalismo (1807-1890), eds. Luís Reis Torgal y João Lourenço Roque (Lisboa: Estampa, 1998), 156.

${ }^{2}$ Referimo-nos ao movimento sebastianista sufocado em 26 de outubro de 1820 na serra do Rodeador, em Bonito, em Pernambuco, distante cerca de $134 \mathrm{~km}$ do Recife. Os camponeses ali organizados criam no retorno de d. Sebastião, rei português morto em 1578 em combate com os islamitas, um rei libertador que segundo a crença ia inaugurar com sua volta um tempo de fartura e felicidade. Flavio José Gomes Cabral, Paraíso terreal: a rebelião sebastianista na serra do Rodeador. Pernambuco - 1820 (São Paulo: Annablume,2004). 
recrutadas para aquela empreitada, diante da novidade, resolveu ficar no Recife. Seu objetivo, ao tomar essa decisão, era contornar possíveis levantes em solidariedade ao movimento português, por entender que os comentários de rua poderiam funcionar como canais de opiniões e gerar tomadas de atitude. Além do falatório, se tornaram constantes, no período em estudo, a ação panfletária e outras manifestações mais difíceis de ser captadas em registro, como, por exemplo, vozes, gritos, canções e gestos, que tanto tiraram o sono do governador da época e consistiam no que a historiadora francesa Arlette Farge nomeou de "opinião pública" ${ }^{3}$. Isso faz entender o porquê de o espaço colonial ter desenvolvido a opressão e de terem sido criadas ali condições para que se excedessem os limites que, para a Coroa, eram sua própria salvaguarda ${ }^{4}$.

O processo iniciado na cidade do Porto em 1820 foi resultado de uma espécie de desapontamento quase que generalizado do lusitano diante da situação vexatória com que se viu obrigado a conviver desde as invasões francesas, quando a sede administrativa do reino foi transferida para a América portuguesa, de onde as ordens passaram a vir, além da crise econômica em que se viu mergulhado. De acordo com Vargues sintetizando os sentimentos vividos pelos portugueses a partir da experiência iniciada em 1820, foi um momento em que se falou de liberdade contra o despotismo e de regeneração contra a decadência ${ }^{5}$. Essas seriam as palavras-chave que serviriam para ilustrar o movimento vintista, nome pelo qual ficou conhecido o pensamento político iniciado em 1820.

Pelos comandantes do navio inglês, o governador Luís do Rego Barreto recebeu, além das notícias, mensagens dos governadores do reino de Portugal, explicando as mudanças políticas implantadas pela revolução liberal. Diante da gravidade da situação, achou prudente escrever à corte do Rio de Janeiro (para onde a família real portuguesa fugira da invasão napoleônica em 1808) lamentando as últimas ocorrências dizendo "quanto cuidado requerem as coisas do Brasil", alertou Luís do Rego Barreto. Portugal, sob efeito da revolução constitucionalista, organizou uma Junta Provisional de Governo, que de imediato comunicou a d. João VI no Rio de Janeiro as novas estruturas políticas, entre elas a decisão de se convocar as cortes. Procedeu-se ainda à nomeação de várias comissões encarregadas de reformar a administração do império português. Nesse interregno, foi dado o primeiro passo para a preparação das primeiras eleições em Portugal e posteriormente para as possessões em ultramar. Em 31 de outubro de 1820, por

\footnotetext{
${ }^{3}$ Arlette Farge, Dire et mal dire: l'opinion publique au XVIIIe siècle (Paris: Seuil, 1992).

${ }^{4}$ István Jancsó y João Paulo G Pimenta, "Peças de um mosaico (ou apontamento para o estudo da emergência da identidade nacional brasileira)", en Viagem Incompleta. A experiência brasileira (1500-2000). Formação: histórica, ed. Carlos Guilherme Mota, 2a ed. (São Paulo: Senac, 2000), 54.

${ }_{5}^{5}$ Isabel Nobre Vargues, A aprendizagem da cidadania em Portugal - 1820-1823 (Coimbra: Minerva, 1997), 29.
} 
intermédio de um "manifesto", foi apresentada a nação portuguesa a idéia de corte como representação nacional, abrindo-se $\mathrm{o}$ caminho em torno do constitucionalismo.

Para José Honório Rodrigues, o movimento era conservador porque não pensou na instalação do republicanismo e estava associado ao liberalismo econômico ${ }^{6}$. Um liberalismo que procurou manter as dependências brasileiras, que não via subjugação aos ingleses, impondo algumas regras limitativas ao monarca. Naquele ano, observou Maxwell o Brasil se encontrava independente econômica e politicamente desde 1808 e a partir de 1815 fazia parte de um reino unido, em pé de igualdade com Portugal ${ }^{7}$. Para o referido escritor, o que estava em jogo naquele ano era a questão relacionada com a monarquia, a continuação e a integridade territorial, e não com a revolução colonial. Em circunstância talvez rara, o ano de 1820 representou para Portugal seu grito de independência do Brasil, e só depois, em 1822, o Brasil declarou sua "independência" de Portugal. Não obstante, a proposta vintista foi promover uma regeneração política e administrativa que pudesse reformar a ordem das coisas substituindo antigas práticas alicerçadas no Antigo Regime pelas do liberalismo, embora sob a ótica das "mitigadas luzes ibéricas" $"$.

Os revolucionários de 1820 tinham consciência de que o futuro da Regeneração dependia da união de todo o território português, inclusive o Brasil, em face de seus produtos terem lugar de destaque no montante do comércio de todo o império português. Entretanto, segundo ${ }^{9}$ parecia impossível harmonizar esses interesses de maneira que o Brasil pudesse participar na regeneração econômica do reino sem renunciar a direitos adquiridos. Num momento em que se deslumbrava a olhos

\footnotetext{
${ }^{6}$ José Honório Rodrigues, Independência: revolução e contra-revolução, vol. 1 (Rio de Janeiro: Livraria Francisco Alves, 1975), 31.

7 Kenneth Maxwell, "Por que o Brasil foi diferente? O contexto da independência. Formação: histórias”, en Mota, Viagem incompleta, 186-188.

8 Lúcia Maria Bastos Pereira das Neves, "Liberalismo político no Brasil: idéias, representações e práticas, 1820-1823", en O liberalismo no Brasil imperial: origens, conceitos e práticas, eds. Lúcia Maria Paschoal Guimarães y Maria Emília Prado (Rio de Janeiro: Revan; UERJ, 2001), 76.

${ }^{9} \mathrm{Na}$ realidade, a revolução iniciada no Porto em 1820 agregava homens de quadrantes políticos diversos que pensavam sobretudo em expulsar os invasores franceses, pressionar o retorno do rei para Portugal e reintegrar o Brasil no espaço econômico-político português. Miriam Halpern Pereira, Das revoluções liberais ao Estado Novo (Lisboa: Presença, 1993), 46; Maria Cândida Proença, A independência do Brasil: relações externas portuguesas, 1808-1825 (Lisboa: Livros Horizonte, 1987), 42.
} 
vistos o desarranjo das colônias sul-americanas, quando todas elas lutavam pela independência, não se poderia esperar que o Brasil cedesse tais direitos ${ }^{10}$.

No Recife, ao que tudo indica, certas novidades, como a Revolução do Porto, causavam grande impacto. Geralmente elas se propagavam de vários pontos, sendo o principal deles o movimentado porto da cidade, um dos mais importantes do Nordeste do Brasil. Era ali que desembarcavam passageiros, funcionários reais, correspondências e impressos. Ao sinal da chegada de uma embarcação na barra do horizonte, os habitantes da cidade corriam até o cais à procura de informações. Isso não foi diferente quando da chegada do navio Chresterfiel. Koster ${ }^{11}$ viajante inglês dos princípios dos oitocentos, guardou na memória e escreveu posteriormente essas cenas, relatando o agito das pessoas no porto à procura de novidades e notícia dos amigos e parentes que estavam na Europa. Naquele momento em que o Ancien Régime dava sinais de agonia, Luís do Rego passou a ficar "atento aos progressos da opinião [pública]", chegando a confidenciar por carta a Tomás Antônio Vila Nova Portugal, que servia ao reino como ministro dos Negócios Estrangeiros e da Guerra, que o espírito público era o que lhe serviria "de barômetro"12. Agiria no momento certo, silenciando mediante coações quem esboçasse resistência. Por isso, infiltrou no meio da rua uma rede de espionagem, a fim de colher informações sobre o estado de ânimo dos pernambucanos.

Muito antes da chegada das primeiras notícias sobre a revolução vintista portuguesa visivelmente inspirado na experiência espanhola, os movimentos liberais europeus foram comentados no Brasil. O governador acusava os ingleses de espalhar jornais europeus com novidades acerca desses acontecimentos, cujas matérias eram derramadas "como matéria elétrica" e ajudavam a "levantar incêndio em outras partes" da província ${ }^{13}$. É verdade que só uma pequena parte da população local tinha acesso àquelas leituras. Entretanto, quando o público letrado lia e comentava com amigos, nas esquinas e nos cafés, o conteúdo daquelas folhas, as conversas eram escutadas pelos transeuntes, que transmitiam a outros, acrescentando interpretações ${ }^{14}$. As várias cartas endereçadas ao ministro Tomás

${ }^{10}$ Sobre o desmonte do império espanhol no continente americano, leiam-se: Antonio Annino y François-Xavier Guerra, eds., Inventando la nación iberoamérica. Siglo XIX (México: Fondo de Cultura Económica, 2003).

${ }^{11}$ Henry Koster, Viagens ao nordeste do Brasil, 11 ${ }^{\mathrm{a}}$ ed. (Recife: Fundação Joaquim Nabuco; Massangana, 2002), 1: 66.

12 "Cartas Pernambucanas de Luís do Rego Barreto", Revista do Instituto Arqueológico, Histórico e Geográfico Pernambucano (Recife), 52 (1979): 169.

${ }^{13}$ Ibídem, 175.

${ }^{14}$ Neste texto, inspiro-me em Darnton, estudioso da França pré-revolucionária. Segundo ele, as notícias fascinaram os parisienses, que, mesmo vigiados, encontraram métodos para se comunicar e comentar as novidades palacianas e os assuntos políticos. Robert Darnton, Os best-sellers proibidos da França pré-revolucionária (São Paulo: Companhia das Letras, 
Antônio Vila Nova Portugal por Luís do Rego demonstravam receio de que as "vozes públicas" opinassem sobre assuntos políticos. Em virtude disso, dizia o governador viver em Pernambuco como os "cavaleiros da Távola Redonda, vestido dia e noite, armado de todas as armas e pronto a voar" para onde seus deveres o chamavam $^{15}$.

O movimento vintista possibilitou o uso de um novo léxico político nos dois lados do Atlântico que exprimiam uma prática constitucional. Mas, na realidade, o entendimento parecia complicado para algumas pessoas: cortes, juntas provisórias de governo, eleição, voto, eleitor, deputado, cidadão, corcunda (partidário dos portugueses e da monarquia absoluta), constituição e regeneração. Esta última era a palavra-chave do momento, pois exprimia o próprio nome do movimento. Revolução foi à época um termo pouco utilizado e, quando se fazia uso, referia-se à maneira contra-revolucionária levantada a partir de 1820. "Regeneração" significava "reformar" ou "renovar", rompendo-se com parte do passado porque se conservavam a monarquia e o catolicismo ${ }^{16}$. Em contrapartida, outras palavras procuraram explicar os abusos da liberdade: anarquia, guerra civil, pedreiros-livres, carbonários, jacobinos, democracia, república, partido e facção ${ }^{17}$. Em Pernambuco, tomou-se cautela quanto à "propagação das doutrinas constitucionais". Mesmo assim, às escondidas comentava-se pelas esquinas a "mudança do sistema, da Constituição, das Cortes", etc ${ }^{18}$.

No Recife dos princípios dos mil e oitocentos, segundo podemos deduzir com base nas fontes consultadas, debatiam-se idéias e comentavam-se novidades, principalmente porque existia um público letrado que se envolvia em assuntos de política, tinha influência nas tomadas de decisão e poderia encabeçar futuros intentos de rebeldia a exemplo do que aconteceu em $1817^{19}$. Esses debates se

1998); "Uma precoce sociedade da informação", Varia História (Belo Horizonte), 25 (julio 2001): 9-51.

15 "Cartas Pernambucanas", 215.

${ }^{16}$ Ribeiro, A liberdade em construção, 111.

${ }^{17}$ Guilherme Ferreira das Neves, "Del império lusobrasileño al imperio del Brasil (17891822)", en Annino, Inventando la nación, 169.

${ }^{18}$ Luís do Rego Barreto, Memória justificativa sobre a conducta do marechal de campo Luiz do Rego Barreto durante o tempo em que foi governador de Pernambuco, e presidente da junta constitucional do governo da mesma província (Lisboa: Typographia de Desiderio Marques Leão, 1822), 25.

${ }^{19}$ Em 6 de março a maio de 1817, enfrentou d. João VI no Nordeste do Brasil uma revolta, iniciada em Pernambuco e com focos na Paraíba, Rio Grande do Norte e Ceará, denominada pelos revoltosos de revolução, que propôs e concretizou, pelo espaço de 74 dias, o fim do domínio real naquelas regiões. Em Pernambuco, o poder foi tomado do governador Caetano Pinto de Miranda Montenegro e, no Recife, foi organizado um governo baseado no modelo republicano do diretório da Revolução Francesa. Entre as lideranças do movimento, destacam-se padres, comerciantes, senhores de terra e de escravos. Na verdade, 
davam nas portas das igrejas, nas academias, nos mercados públicos, nos cafés e nos bares ${ }^{20}$. Afora esses ambientes, as conversas partiam das ruas, uma vez que nem todos tinham acesso a eles. Certa feita, observou Koster ${ }^{21}$ as ruas do Recife lotadas de gente que circulava pelo comércio, ambiente propício para conversas e encontros fortuitos ou de negócios. Além dos citados espaços de convivência, a vila do Recife desde cedo passou a conviver com outro espaço, as águas do rio Capibaribe, que a emoldura. O rio servia de estrada por onde diariamente circulavam canoas transportando pessoas, objetos e coisas ${ }^{22}$. De um trajeto a outro, canoeiros e passageiros jogavam conversa fora e muitos assuntos vinham à tona durante a viagem. Assim, pelas "águas do Recife", parafraseando Marcus Carvalho $^{23}$, muita coisa se passava. Aliás, esse autor sugere que entre o Recife e as águas do rio Capibaribe existiu um vínculo, e isso se tornou um dos aspectos mais particulares do lugar, muito diferente de outros centros importantes brasileiros, como Salvador e Rio de Janeiro, então sede da corte portuguesa desde 1808 com a chegada da família real portuguesa.

O governador de certa forma confiava em seus velhos métodos de coerção, por entender que "só o medo" podia reprimir "as vozes públicas"24. Diante do adensamento de opiniões em torno do panorama político do momento e temendo um levante na província, procurou cortar as comunicações com Portugal, evitando que navios pernambucanos cruzassem o Atlântico. Tal medida foi recebida com

essas pessoas não estavam interessadas em implantar na região um modelo republicano de participação popular, mas em continuar usufruindo os direitos conquistados desde os tempos da colonização do Brasil. Apesar da adesão das províncias citadas, faltaram ao movimento participação da população e um melhor preparo militar. Desmontada a República pela ação da Coroa o movimento em destaque representou no dizer de Carlos Guilherme Mota "o primeiro traço realmente significativo de descolonização acelerada e radical". Carlos Guilherme Mota, Nordeste 1817: estruturas e argumentos (São Paulo: Perspectiva, 1972), 2. O novo governador, Luís do Rego Barreto, conduziu com eficácia o desmente do movimento, punindo os rebeldes com prisões e até à condenação à morte. Glacyra Lazzari Leite, Pernambuco 1817: estruturas e comportamentos sociais (Recife: Fundação Joaquim Nabuco; Massangana, 1998).

20 Sobre a importância dessa rede de sociabilidade na formação cultural e política pernambucana, veja-se: Denis Antônio de Mendonça Bernardes, "O patriotismo constitucional: Pernambuco, 1820-1822” (Tesis doctoral, Universidade de São Paulo, São Paulo, 2001), 87-149.

${ }^{21}$ Koster, Viagens ao nordeste, 66.

${ }^{22}$ Sobre a importância dos canoeiros na paisagem pernambucana, leia-se: Luiz Geraldo Silva, A faina, a festa e o rito: uma etnografia histórica sobre as gentes do mar (sécs. XVII ao XIX) (Campinas: Papirus, 2001), 119-154. Veja principalmente o capítulo 5, Condução, carreira e água.

${ }^{23}$ Marcus Carvalho, Liberdade: rotinas e rupturas do escravismo no Recife, 1822-1850 (Recife: UFPE, 1998), 21-40.

24 "Cartas Pernambucanas", 176. 
descontentamento pelos negociantes, principalmente os ingleses, que viram nessa atitude sinais de prejuízo ${ }^{25}$. Em virtude da celeuma, e como a Coroa não se pronunciava quanto a essa drástica determinação, o governador resolveu desistir do ato porque foi informado de que na província da Bahia não houve ação semelhante e os navios daquela província continuaram a abastecer Portugal como antes. $\mathrm{Na}$ província do Ceará quando seu governador recebeu, por intermédio do colega pernambucano, informações de que "na cidade do Porto deram princípio ao horrendo crime de rebelião contra o poder e autoridade de Sua Majestade", imediatamente proibiu a saída de navios daquela província para a cidade do Porto, permitindo, no entanto, que tais cargueiros se dirigissem apenas para Lisboa, sob a condição de "primeiro tocarem nas Ilhas dos Açores, a saber notícias""26.

Um dos efeitos imediatos da Revolução do Porto no Brasil veio da província do Pará, que em $1^{\circ}$ de janeiro de 1821 aderiu ao movimento liberal, sendo seguido pela província da Bahia (10 de fevereiro). Entretanto, foi em Pernambuco, ainda sob o impacto das primeiras notícias vindas da Europa, quando não se tinha conhecimento cristalino do que se passava do outro lado do Atlântico, que se organizou, no Recife, uma sedição urdida por militares, em sua maioria de procedência portuguesa, para rebentar em meados de novembro de 1820 por ocasião da festa de Santo André. Faz-se necessária aqui uma observação. É de se estranhar o descaso da historiografia brasileira sobre esse assunto, que, tudo indica, se trata de uma das primeiras manifestações de adesão ao movimento constitucional iniciado em Portugal em 1820. Tanto que só pudemos tecer alguns esclarecimentos acerca da referida sedição graças a uma devassa aberta pelo governador da época para conhecer com mais nitidez as idéias e as pretensões dos amotinados. Nos dias em que se tecia a sedição, panfletos manuscritos foram espalhados pelas ruas recifenses insuflando o público leitor. Um deles, escrito em forma codificada, arrancado das mãos de um soldado, depois decifrado pelos agentes da repressão, acusou o absolutismo monárquico de barrar as aspirações sociais:

Insano aonde te leva o teu desvario! Que fanáticos prejuízos te roubam a razão! Acaso é para ti mais sagrado o sustentar o despotismo de um só homem que contribuíres à felicidade da pátria e dos teus compatriotas? $\mathrm{Tu}$ abandonaste e destruíste um nascente partido que devias apóias, crime que devia ser punido e que só por compaixão pode ficar impune; acorda e pensa que tu podes fazer o teu nome grande, sendo eterna a gratidão dos teus compatriotas; prejuízos de educação te deslumbram e te fazem sacrificar o teu interesse, a tua fama, a tua glória e a felicidade de um país inteiro a um só homem;

\footnotetext{
${ }^{25}$ Ibídem.

${ }^{26}$ Archivo Nacional do Rio de Janeiro -en adelante ANRJ- (Rio de Janeiro), IG1-34.
} 
reflete e te sirva de luz esta última advertência, pois quando insistas no teu desvario, será um assassino que te desperte, porém tarde, do letargo em que jazes, e que assim alivie a pátria de um filho ingrato que lhe não quer ser útil. Se és homem de bem como deves ser, põe a resposta no mesmo lugar sem ser curioso ${ }^{27}$.

Segundo comentou um dos insurgentes, com a vitória desse movimento, iam ser postas em execução a Constituição e a revolução em Pernambuco, e esta seria capitaneada por um "chefe de algum corpo [militar]" ${ }^{28}$. João Botelho Noblis foi um desses entusiastas. Ao ser preso, esclareceu que em uma das reuniões secretas de que participou falou-se em Constituição e da necessidade de se inaugurar em Pernambuco um tipo de governo igual ao que fora instalado em Portugal. Dessa forma, entende-se que os insurgentes almejavam implantar aqui uma junta provisional de governo em substituição ao governo de Luís do Rego Barreto. Tais governos foram estabelecidos em diversas províncias do império português em apoio e fidelidade à política do soberano Congresso durante o período de $1821 \mathrm{e}$ 1822.

Certo dia de novembro de 1820 o soldado Manuel Marques Lisboa e João Botelho Noblis foram à cidade de Olinda tentar uma adesão importante, a do tenente Felipe Néri de Barcelos, que tinha muita influência nos quartéis e prestígio entre os soldados. Na casa de Barcelos, os visitantes expuseram os motivos da revolta, convidaram-no a participar do movimento e o incumbiram da missão de assassinar o português Madureira Lobo, comandante do Segundo Batalhão. No fim da visita, ficou acertado que no lugar de Fora de Porta, lugar ermo próximo do porto local, onde morava Marcos de Barcelos, irmão do tenente Barcelos, se faria uma reunião secreta com a participação de várias pessoas, entre elas o português Antônio de Morais Correa de Sá Castro, considerado o principal arquiteto da revolta.

A periodicidade de reuniões na casa de Marcos de Barcelos, situada em Fora de Portas despertou a atenção da vizinhança. D. Evangelista Salgueiro foi uma delas. Segundo ela, foram as mesmas "pessoas esquisitas e de farda que com freqüência ali se reuniram" 29 . D. Francisca Maria dos Prazeres, esposa de Marcos de Barcelos, ao ser chamada para depor, confessou que no dia 26 de novembro de 1820, após o meio-dia, dois homens estiveram em sua casa, um deles "ainda moço de cabelo ruivo" e o outro aparentando certa idade, devendo-se tratar do coronel Sá e Castro. Foram até ali para avisar o seu marido de "que tudo estava pronto" e que a hora da revolução era chegada ${ }^{30}$. À noitinha daquele mesmo dia, foi a sedição denunciada

\footnotetext{
${ }^{27}$ ANRJ (Rio de Janeiro), IJJ9, fol. 187.

${ }^{28}$ Ibídem, fol. 199.

${ }^{29}$ Ibídem, fol. 389.

${ }^{30}$ Ibídem, fol. 249v.
} 
às autoridades provinciais. Uma carta anônima endereçada ao governador apontou nomes e não poupou o Batalhão dos Algarves ${ }^{31}$, composto de oficiais portugueses que atravessaram o Atlântico para dar cobertura ao governo no desbarate à revolução de 1817. Em breve espaço de tempo, vários suspeitos foram presos.

Conforme planejado, no dia preparado para a eclosão do motim, após o alarme, homens experimentados iriam até a casa do governador, no sítio do Mondego, no bairro da Boa Vista, e poriam em execução o assassinato dele e do secretário do governo. Nesse interregno, o palácio seria tomado, ocorrendo o mesmo com os Fortes do Brum e do Buraco, tidos como os mais importantes ${ }^{32}$. Esperava-se que no espaço de 24 horas a nova ordem política estivesse instalada com a realização de prisões e de mortes que se achassem necessárias. No momento em que soassem os alarmes, o povo seria despertado, quando então as principais vias de acesso ao Recife seriam bloqueadas. No Forte das Cinco Pontas, como já esboçado, presos e soldados, alguns dos quais avisados, insurgiram simulando uma rebelião.

$\mathrm{Na}$ tarde do dia 26 de novembro de 1820, antes mesmo de uma reunião secreta acertada para a noite daquele dia, o comandante das brigadas de artilharia do Recife, o coronel Joaquim Pedro Dias Azevedo, ao tomar conhecimento da conspiração por intermédio de Felipe Néri de Barcelos que o havia convidado para tomar parte do movimento, denunciou ao governo a revolta. Soldados invadiram a casa de vários insurgentes entre elas a residência de José Fernandes Gama, amigo do coronel Antônio de Morais de Sá Castro, e confiscando alguns de seus bens, entre eles cartas dirigidas a um certo Bernardino José Coelho, "todas cheias de insulto e impropérios dirigidos especialmente contra mim", disse Luís do Rego Barreto $^{33}$. O prisioneiro não negou ser o proprietário das correspondências, chegando a declarar que elas só continham "verdades públicas".

O inquérito instaurado contra os rebeldes concluiu que o desejo "dos desgraçados conspiradores" era fazer uma mudança no governo "de Vossa Majestade", pois eles falavam em constituição sem que cada um deles pudesse ligar idéia a esta palavra. Mesmo não desejando os rebeldes a fragmentação do Reino Unido, posição em que

${ }^{31}$ Recrutado em Portugal, o soldado lusitano, ao chegar aqui, além de ter a obrigação de defender os interesses do rei, se via obrigado a atender também aos interesses das elites locais, o que gerou entre eles descontentamento. Marcus J. M. de Carvalho, "Os militares e a revolução de 1817 em Pernambuco". Anais da XVII Reunião da Sociedade Brasileira de Pesquisa Histórica (São Paulo: SBPH, 1997), 201. A insatisfação desses soldados era tamanha, que muitos desertavam do batalhão. Em 1819, tem-se notícia da deserção do soldado Francisco Manoel, quando, por portaria do comandante daquele batalhão, o dito desertor foi levado a conselho de guerra devido à sua falta. Archivo Público Estadual Jordão Emerenciano -en adelante APEJE- (Recife), R. PRO 7/4, fol. 12.

${ }^{32}$ ANRJ (Rio de Janeiro), IJJ9, fols. 196-198.

${ }^{33}$ Ibídem, fol. 204v. 
passou o Brasil a figurar no império português a partir de 1815 , por tentarem instaurar em Pernambuco um governo que negava o absolutismo, quatro dos envolvidos na revolta foram incursos no crime de lesa-majestade e por isso expulsos da província: coronel Antônio de Morais Correa de Sá e Castro foi remetido para a ilha de São Tomé; João Botelho Noblis, para Angola; o comandante José de Sá Carneiro Pereira, para a província brasileira de Sergipe delRei; o comandante João Casemiro Pereira Rocha, para a Índia. Caberia aos governadores desses lugares a responsabilidade pela guarda dos prisioneiros, conservando-os em "prisão onde deveriam esperar a sentença que houvesse de seus crimes" 34 .

Pela maneira como o movimento foi articulado, parecia tratar-se de um ensaio sedicioso, segundo sugere Jancsó ${ }^{35}$ em instigante artigo intitulado "A sedução da liberdade". Para ele, tais comportamentos de natureza subversiva desejavam proclamar a "revolução desejada, o futuro anunciado, a política do futuro nos interstícios do presente". Tais agitações ultrapassaram os limites dos habituais motins em razão dos excessos fiscais ou de soldados reclamando o pagamento do soldo em atraso. Esses intentos de rebeldia, além de negar o absolutismo monárquico, "anunciavam a erosão de um modo de vida" encaixado numa conjuntura mais dilatada da crise do Antigo Regime.

Tomando a população conhecimento desses planos sediciosos, um desses gaiatos, aproveitando o ensejo, cruzou as Ruas da Trempe e da Soledade, que ficavam contíguas à moradia do governador, e deixou impresso um verso escrito em tinta preta sobre o muro pintado de branco: "Toma cautela, Rego/ Não passes no Mondego" ${ }^{36}$. Após o desmonte da rebelião, muita coisa começou a se passar na cabeça dos habitantes de Pernambuco quanto ao futuro político da província, porque o Batalhão dos Algarves não se mostrava favorável a abraçar a causa liberal. Os absolutistas locais, amigos do governador, também não demonstravam sensibilidade para mudar a ordem das coisas, preferindo deixar tudo como estava ${ }^{37}$. O homem do interior, ainda abalado pelas lembranças da revolução de 1817 , parecia confundir governo constitucional com governo republicano, pensando que as reformas pretendidas eram iguais às de 1817. O medo que o Sul do Brasil se declarasse novamente contra a província de Pernambuco, como ocorrera havia três

\footnotetext{
${ }^{34}$ Ibídem, fol. 190.

${ }^{35}$ István Jancsó, "A sedução da liberdade: cotidiano e contestação política no final do século XVIII", en História da vida privada no Brasil: Cotidiano e vida privada na América portuguesa, ed. Laura de Mello e Souza (São Paulo: Companhia das Letras, 1997), 1: 388-437.

${ }^{36}$ Pereira da Costa, Anais pernambucanos, 1795-1817 (Recife: Arquivo Público Estadual, 1958), 486.

${ }^{37}$ Francisco Pacífico do Amaral, Escavações: fatos da história de Pernambuco, $2^{\mathrm{a}}$ ed. (Recife: Arquivo Público Estadual, 1974), 44.
} 
anos, deixou muita gente confusa em continuar a bater no despotismo de Luís do Rego Barreto.

Segundo se pode perceber nas correspondências oficiais, havia em Pernambuco, e quiçá pelo Brasil, dois canais de opiniões, o dos centros urbanos e o do interior. Naquele residia uma população composta de oficiais liberais, comerciantes e funcionários públicos, que quase sempre se deixavam seduzir pelos ideais liberais. No interior, o homem rural, alheio às teorias liberais, resistia às mudanças e muitas vezes se posicionava ao lado dos chefes absolutos patriarcais. Da povoação de Panelas de Miranda, comunidade implantada no agreste meridional de Pernambuco, veio o exemplo quando se tomou conhecimento das novidades políticas surgidas na esteira dos acontecimentos vintistas: homens empunhando a bandeira real invadiram as povoações de Altinho, Bebedor e Prata e, aos gritos, diziam que não desejavam a Constituição ${ }^{38}$. Tal palavra no interior do Ceará, segundo informe de Emília Viotti" ${ }^{39}$, gerou polêmica e foi entendida como "uma inovação da forma de governo em prejuízo do rei e, portanto, uma impiedade, um atentado contra a religião". Na vila Brejo da Areia, situada na província da Paraíba, houve alvoroço e até quem gritasse que não queria "governo patriótico", preferindo-se o "Rei Velho", isto é a manutenção da coroa bragantina cingida em d. João $\mathrm{VI}^{40}$. Por causa da falta de informação do povo, o rei mandou a diocese da cidade de Olinda editar pastorais esclarecendo aos seus diocesanos "que a Constituição em nada se opõem à religião, antes lhe dá maior esplendor" ${ }^{\prime 41}$.

Essas tramas mostram que a Independência do Brasil foi o resultado de um processo que foi evoluindo com o passar dos dias, resultado de um jogo de batalha e reações entre as cortes portuguesas e as elites brasileiras, no interior de um mesmo universo mental. Tais discussões estimularam a circulação de periódicos e panfletos, muitos dos quais vindos de Portugal, que de certa forma procuraram

\footnotetext{
38 “Carta-resposta do capitão Manoel Bezerra de Melo ao capitão-mor de Santo Antão João Luís da Rocha, escrita no quartel de Bonito em 17 de abril de 1822”. APEJE (Recife), Ord. 2, 1821-1822.

${ }^{39}$ Carlos Guilherme Mota, ed., Brasil em perspectiva, 12ª ed. (São Paulo: Difel, 1981), 100-1001.

${ }^{40}$ Archivo Histórico Ultramarino -en adelante AHU- (Lisboa), maço 38.

41 "Carta do vigário capitular ao rei” (21 de enero de 1822), AHU (Lisboa), ACL_CU_015, caja 285, doc. 19480. Na prática, essa carta referendava um dos itens do "Manifesto aos portugueses", assinado pela Junta Provisional do Governo Supremo do Reino e datado de 24 de agosto de 1820, que dizia ao povo que as mudanças pretendidas não atacariam a religião; pelo contrário, esta ganharia mais brilho, "e a melhoria dos costumes, fruto também de uma iluminada instrução pública, até hoje por desgraça abandonada, fará a nossa felicidade e das idades futuras". Manuel Fernandes Tomás, A revolução de 1820, Coleção Universitária núm. 2, 2ª ed. (Lisboa: Caminho, 1982), 48.
} 
esclarecer ao público leitor as mensagens do vintismo. No ano de 1821, segundo Guilherme Pereira das Neves:

Los debates giraron en torno al constitucionalismo, procurando explicar, incluso desde el púlpito, el significado de las ideas en juego, criticar a los partidarios del absolutismo y aclarar a los electores el tipo de responsabilidades que se veían investidos. En su mayoría, la elite brasileña se identificaba con los revolucionarios de Portugal y se entregaba en cuerpo y alma a extender el 'sistema liberal' a la porción americana del imperio ${ }^{42}$.

Todo esse clima tenso continuou até o dia 2 de março de 1821, quando, por volta das 9 horas da manhã, tomou-se conhecimento em Pernambuco de que a Bahia havia instituído um novo governo em 10 de fevereiro, declarando-se desligada do governo do Rio de Janeiro e solidária às cortes de Lisboa ${ }^{43}$. De ouvido em ouvido, a novidade foi tomando vulto, e ao meio-dia não havia quem a ignorasse. Nas esquinas das ruas falava-se em "Constituição e cortes de Portugal; acolá, na independência absoluta do Brasil; outro clamava pela Constituição política dos Estados americanos"44. A adesão da Bahia, do Rio de Janeiro e as tentativas sediciosas aqui registradas em apoio às cortes lisboetas são evidências do equívoco cometido pelo autor de um panfleto escrito em francês, em 1821, no Rio de Janeiro, dizendo que, se houvesse a separação do Reino Unido, o Brasil permaneceria fiel à monarquia absolutista ${ }^{45}$. Para o autor, os brasileiros, mesmo queixosos, não pensavam em mudar a ordem política. Entretanto, ele generalizou e não percebeu que no Brasil não havia, como escrevemos alhures, uniformidade de opinião nem nos centros urbanos e tampouco no interior ${ }^{46}$.

${ }^{42}$ Annino, Inventando la nación, 248-249.

${ }^{43}$ Zélia Cavalcanti, "O processo de independência na Bahia", en 1822 dimensões, Carlos Guilherme Mota (São Paulo: Perspectiva, 1986), 236. Sobre o processo de independência na Bahia, leiam-se: Argemiro Ribeiro de Souza Filho, "As juntas governativas e a independência: 'multiplicidade de poder' na Bahia", en As múltiplas dimensões da política e da narrativa, eds. Teresa Malatian, Marisa Saenz Leme, Ivan Aparecido Manoel (Franca y São Paulo: UNESP/ Olho d'Água, 2004), 51-63 y Maria Aparecida Silva de Souza, "Nação, pátria e império: as câmaras municipais baianas e a independência", en $A s$ múltiplas dimensões da política e da narrativa, eds. Teresa Malatian, Marisa Saenz Leme, Ivan Aparecido Manoel (Franca y São Paulo: UNESP/ Olho d'Água, 2004), 65-75.

44 "Cartas Pernambucanas", 192.

${ }^{45} \mathrm{O}$ opúsculo se intitulava: "Le roi et la famille royale de bragance, doivent-ils, dans les circonstances présentes, retourner en Portugal, ou bien rester au Brèsil?". Biblioteca Nacional do Rio de Janeiro -en adelante BNRJ- (Rio de Janeiro), Div. Manuscritos, I-35, $10,011$.

${ }^{46}$ Kenneth Maxwell, "A política”, en O império luso-brasileiro-1750-1822, ed. Maria Beatriz Nizza da Silva, (Lisboa: Estampa, 1986), 8: 403-405. 
Diante da falta de tranqüilidade pública, viu-se o governador obrigado a propor na Junta da Real Fazenda aumento do soldo das tropas de linha, porque o novo governo da Bahia "aumentara consideravelmente o soldo dos [seus] oficiais", deixando descontentes os soldados pernambucanos, que exigiam equiparação àqueles ${ }^{47}$. Em meio a tantas agitações, circularam rumores de que um motim estava projetado para rebentar durante a procissão de Cinzas. A partir desse momento, resolveu Luís do Rego não mais esperar pelo rei e, em 29 de março de 1821, convocou as autoridades civis, militares e eclesiásticas para opinar sobre os negócios públicos em ocasiões de crise. Nessa reunião, contrariando as perspectivas de setores da população, decidiu-se criar uma junta constitucional governativa, conservando Luís do Rego no poder. Os ânimos voltaram a se exaltar quando aqui chegaram o Decreto de 18 de abril de 1821 das Cortes Gerais e Constituintes da Nação Portuguesa, que declarava legítimos os governos estabelecidos ou que se estabelecessem, bem como considerava beneméritos da pátria os cidadãos que promovessem a causa da regeneração política da nação portuguesa. Punia o referido decreto todos aqueles que se opusessem a essa causa, responsabilizando-os pelos males que pudessem causar à nação ${ }^{48}$. De qualquer forma, estava dado em Pernambuco um grito de revolta. Além dos pasquins que circularam clandestinamente apontando os atos arbitrários de Luís do Rego, houve aqueles que escreveram para o Rio denunciando ao príncipe regente tais atitudes ${ }^{49}$.

Vários conflitos foram registrados no Recife. Na realidade, os mexericos se propagavam mediante falatórios, pasquins manuscritos, cartas e pichações nos muros. Por causa disso, o governador editou uma proclamação ao povo pernambucano recomendando cautela e obediência ao monarca ${ }^{50}$. Carlos Guilherme Mota ${ }^{51}$, investigando as várias teias sediciosas existentes no Brasil dos fins do século XVIII aos princípios do século seguinte, notou a opinião pública muitas vezes se posicionando a favor dos rebeldes, porque, segundo o autor, "a opinião pública já se torna influenciável, fácil de ser orientada no sentido de incompatibilidade com os governos". Nesses barulhos públicos, quando se pedia a morte dos partidários do Antigo Regime - os corcundas - e se cantava o hino constitucional, em nenhum momento se falou na fragmentação do Reino Unido.

\footnotetext{
${ }^{47}$ APEJE (Recife), CC, fol. 2v.

48 Pereira da Costa, Anais pernambucanos, 1818-1823, Coleção Pernambucana, $2^{\mathrm{a}}$ ed (Recife: Fundarpe, 1984,) 8: 128.

${ }^{49}$ APEJE (Recife), OR, 41, fol. 120.

${ }^{50}$ AHU (Lisboa), ACL_CU_015, caja, 282, doc. 19218. Sobre esses episódios, escreveu o comandante da fragata Princesa Real de passagem pelo Recife ao secretário da regência do reino de Portugal na repartição da marinha, carta datada de $1^{\circ}$ de abril de 1821 , em que relata tais reações e receio de que esses tumultos se transformassem em coisa mais séria. Ibídem, doc. 19219.

${ }^{51}$ Carlos Guilherme Mota, Idéia de revolução no Brasil, 1789-1801, $4^{\mathrm{a}}$ ed. (São Paulo: Ática, 1996), 42.
} 
Desejava-se o Brasil unido a Portugal sob a coroa de D. João VI, rei constitucional $^{52}$.

Levando-se em conta as dimensões continentais do Brasil, que inviabilizava uma rápida unidade de intenção das muitas lideranças locais, dá para perceber a coexistência de dois centros de poder surgidos a partir da revolução de 1820: o Rio de Janeiro, sede do governo absolutista, e Portugal, onde estavam as cortes que em um dado momento apresentavam-se como liberais constitucionais em oposição ao monarca absolutista ${ }^{53}$.

Sob o calor de vários alvoroços, a praça pública testemunhava, em 6 de maio de 1821, o desembarque de alguns pernambucanos, paraibanos e potiguares que haviam deixado os cárceres baianos, presos por terem se envolvido no levante de 1817, e que agora, indultados diante dos novos ares políticos, voltavam às suas terras, sendo no Recife recebidos com homenagens. No dia 29 de maio, por exemplo, assistiu-se ao Te-Déum em ação de graças na Igreja de Nossa Senhora do Carmo, por não ceder o pároco da freguesia de Santo Antônio a igreja matriz para aquela finalidade. Foi tamanha a concorrência do ato religioso, que se distribuíram mais de 500 tochas, que mal deram para a metade das pessoas que compareceram ao evento ${ }^{54}$. Na realidade, toda aquela manifestação não passava de um ato de protesto, já que não se podia atacar diretamente o governador. Luís do Rego assistiu a tudo isso com certa ansiedade, tendo sido inclusive aconselhado a remeter para Lisboa alguns dos mais perigosos daqueles homens.

Nesse interregno, estando os ânimos em chamas, do Rio de Janeiro chegou a notícia de que no dia 26 de fevereiro de 1821 d. João VI havia jurado a Constituição ${ }^{55}$. Prontamente, a praça pública se encheu de povo e tropa. Os sinos das igrejas repicaram. $\mathrm{O}$ estrondo da artilharia das fortalezas e dos navios de guerra dava sinais de contentamento. Imediatamente Luís do Rego mandou reunir no paço da câmara autoridades e em seguida se dirigiu a uma das varandas do edifício, a fim de tornar públicas as novidades vindas do Rio. Logo após, foi oficiado um Te-

${ }^{52}$ Maria de Lourdes Viana Lyra, A utopia do poderoso império: Portugal e Brasil: bastidores da política, 1798-1822 (Rio de Janeiro: Sette Letras, 1994).

${ }^{53}$ Marcus J. M. Carvalho, "Cavalcantis e cavalgados: a formação das alianças políticas em Pernambuco, 1817-1824”, Revista Brasileira de História (São Paulo), 18, núm. 36 (1998): 333.

${ }_{55}^{54}$ Costa, Anais pernambucanos, 144.

55 Tais notícias chegaram a Lisboa na noite de 27 para 28 de abril e puseram fim ao ambiente de insegurança e de ansiedade que pairava sobre os vintista portugueses desde a eclosão da Revolução do Porto. O Senado da Câmara lisboeta mandou um bando anunciar pela cidade o triunfo do movimento constitucional. Alexandre Valentim, Os sentidos do império: a questão nacional e a questão colonial na crise do antigo regime português (Porto: Afrontamento, 1993), 544-545. 
Déum, cantado na matriz do bairro de Santo Antônio, e por três dias consecutivos houve festa no Recife. Tentando não perder tempo, o governador procurou organizar o processo eleitoral em Pernambuco, conforme determinações das cortes. Entretanto, não se pode esquecer que Luís do Rego era um representante do Antigo Regime, por isso não era bem-visto pelas cortes nem pela aristocracia proprietária local, que estava descontente por desejar organizar uma junta de governo, a exemplo do Pará e da Bahia.

Controlando de perto as câmaras de Olinda e do Recife, que formavam uma única comarca, Luís do Rego, em obediência ao decreto das cortes de 18 de abril e por edital lavrado em 23 de maio, fez público o nome dos candidatos pernambucanos a deputação das cortes lisboetas ${ }^{56}$. No dia 7 de junho de 1821 , reuniu-se o eleitorado das comarcas de Olinda e do Recife, que formavam um colegiado composto pelas freguesias da Sé de Olinda, São Pedro Mártir, Maranguape, Igarassu, Sirinhaém, Una e Água Preta, perfazendo um eleitorado de 242 votantes, que elegeram os seguintes deputados ${ }^{57}$ : padre Inácio Pinto de Almeida Castro (irmão do padre Miguelinho, executado por crime de lesa-majestade por ocasião do levante de 1817), Manuel Zeferino dos Santos (futuro presidente da província), Pedro de Araújo Lima (advogado e futuro regente do império), João Ferreira da Silva (colaborador do governo republicano e ausente da província desde 1817), Domingos Malaquias de Aguiar Pires Ferreira (emissário do governo de 1817 nos EUA para a compra de armas), padre Francisco Muniz Tavares (recém-liberto da prisão da Bahia e autor de um livro sobre a Revolução de 1817) e Félix José Tavares de Lira (emissário do governo republicano de 1817 em Buenos Aires) ${ }^{58}$.

Em agosto daquele ano, chegava a Lisboa os representantes de Pernambuco, por sinal os primeiros brasileiros a tomar assento nas cortes. As dificuldades internas e a morosidade de comunicação com o restante da província retardaram as eleições dos representantes da comarca do Sertão do Rio São Francisco nos confins da província, que só ocorreram no dia 6 de dezembro daquele ano, na vila de Garanhuns, sede daquela comarca, saindo eleitos o padre José Teodoro Cordeiro e o padre Serafim Sousa Pereira, falecido antes da posse, sendo substituído pelo suplente Manuel Félix Veras (funcionário público). Mas faltava uma eficiente rede de comunicação no Brasil, além de haver outros contratempos. Quando a maioria da deputação brasileira chegou a Lisboa, muitas das decisões relativas ao Brasil já haviam sido aprovadas pelo Soberano Congresso sem a interferência de nossos

\footnotetext{
${ }^{56}$ APEJE (Recife), Pro 7/5, fol. 1v.

${ }^{57}$ AHU (Lisboa), ACL_CU, 015, caja 284, doc. 19444.

${ }^{58}$ Costa Porto, Os tempos de Gervásio Pires (Recife: Governo do Estado de Pernambuco, 1978), 141. Márcia Berbel, "Pátria e patriotismo em Pernambuco", en Brasil: formação do Estado e da nação, ed. István Jancsó (São Paulo: Hucitec; Unijuí; Fapesp, 2003), 359.
} 
deputados, o que seria "um dos fatores invocados pelos brasileiros para se recusarem a aceitar as deliberações do Congresso" $"$.

Enquanto isso, na capital da Bahia, setores liberais depositaram nas mãos de Francisco Pais Barreto e José de Barros Falcão de Lacerda a tarefa de depor Luís do Rego e em seguida promover a eleição de uma junta. A descoberta desse complô levou à prisão vários acusados. $\mathrm{O}$ Recife viveu novamente dias conturbados, tanto que, na noite de 21 de julho de 1821, Luís do Rego foi vítima de um atentado na Ponte da Boa Vista. Em seguida, o atirador se jogou nas águas do rio Capibaribe. Seu corpo apareceu flutuando dias depois. O cadáver foi retirado das águas por populares que passavam próximo da Ponte Velha e exposto no cais da Rua Nova, não havendo, apesar do prêmio oferecido, quem o reconhecesse. Pelo modo como estava vestido, devia-se tratar de um moço de fino trato, branco, aparentando de 25 a $30 \operatorname{anos}^{60}$. Ferido, ficou Luís do Rego impossibilitado de trabalhar, passando interinamente o governo da província para o tenente-coronel José Joaquim Simões. Este, investido no poder, mandou prender mais de duzentas pessoas acusadas de maquinar a morte do governdor. Um conselho foi instaurado, chegando a deportar para Lisboa 42 prisioneiros, em sua maioria homens ligados a Revolução de 1817. Mal chegaram esses homens a Lisboa, as cortes receberam dos deputados pernambucanos denúncias da ilegalidade daquelas prisões. Diante do momento político, a Casa de Suplicação, em 27 de outubro de 1821, relaxava a prisão dos prisioneiros. A repercussão do caso tomou as páginas de "O portuguez constitucional regenerado", que, além de editar cópia da sentença, aproveitava a deixa para exaltar as magnânimas ações da regeneração portuguesa e os "beneméritos encarregados públicos, que por primeira vez nos mostram que coisa seja a celeridade da Justiça" ${ }^{\text {"61 }}$.

Com a prisão de Pais Barreto e de Falcão de Lacerda, coube a Felipe Mena Calado da Fonseca e Manuel Clemente Cavalcanti, figuras conhecidas pelos seus envolvimentos no levante de 1817 na Paraíba e recém-indultadas, a missão de derrubar Luís do Rego Barreto. Instalados ao norte do Recife, passaram a seduzir as milícias de Paudalho, Tracunhaém e Nazaré, que marcharam sobre Goiana, onde, no dia 29 de agosto de 1821, foi instalado, com o apoio dos proprietários da região, um governo provisório, que se dizia subordinado unicamente às cortes e ao rei $^{62}$. A escolha pela vila de Goiana talvez não deva ter sido obra do acaso. A instalação de um governo ali talvez se deva não só ao fato de aquela vila ter

\footnotetext{
${ }^{59}$ Proença, A independência do Brasil, 46.

${ }^{60}$ APEJE (Recife), OC, fols. 327, 329.

61 "Cartas pernambucanas", 574-576. Sobre as vozes levantadas nas Cortes em defesa dos 42 prisioneiros pernambucanos, Márcia Regina Berbel, A nação como artefato: deputados do Brasil nas cortes portuguesas (1821-1822) (São Paulo: Hucitec; Fapesp, 1999), 99-100.

${ }^{62}$ Evaldo Cabral de Mello, A outra independência: o federalismo pernambucano de 1817 a 1824 (São Paulo: Ed. 34, 2004), 68-69.
} 
condições de comunicação com as vilas e as povoações interioranas, mas também pela facilidade de se poder comunicar com certa facilidade com a Europa ou com o Rio de Janeiro sem necessariamente depender da região portuária do Recife, controlada pelo governador. O governo goianense ficou encarregado de agir enquanto não fosse firmada no Recife sua junta constitucional.

Em 30 de agosto de 1821, o governo de Goiana endereçou a Luís do Rego um ofício deixando claro que aquela junta estava unida para levar até o fim "o plano da regeneração da província" e que a instalação daquele governo era "a prova mais decisiva da resolução constante dos povos". Por outro lado, dizia que o referido governo duraria enquanto não se instalasse no Recife outro governo para "render este atual" ${ }^{\prime 3}$ fazendo com que o capitão-general deixasse de ensangüentar a província. Diante da existência de duas juntas em Pernambuco e na iminência de vir a estourar uma guerra civil, resolveu o governador das armas solicitar às cortes instruções sobre o que deveria fazer caso o conflito caminhasse para uma luta armada $^{64}$. Maria Graham, viajante inglesa, esteve no Recife no calor desses acontecimentos $^{65}$. Segundo ela, na noite de 21 de setembro de 1821 , dois pontos importantes foram atacados: Olinda, ao norte, e Afogados, ao sul. A luta foi acirrada. Das fileiras dos exércitos reais, comandados por Luís do Rego, houve 14 mortes e 35 soldados caíram prisioneiros, enquanto nas hostes de Goiana combaliram 2 soldados e 7 saíram feridos. No intuito de bloquear as comunicações entre os bairros de Santo Antônio e da Boa Vista, os insurgentes cortaram a ponte de madeira ao meio, obrigando os transeuntes a usar "duas pranchas, de fácil remoção, caso os sitiantes se apoderassem desse último bairro". No dia seguinte, segundo testemunhou a viajante, verificou-se logo pela manhã grande pânico entre os recifenses em virtude de terem visto indivíduos amados aguaritados nas igrejas, para onde conduziram munições de guerra.

Em virtude das instabilidades políticas, houve elevação do preço dos principais gêneros alimentícios. Vez por outra, ondas de boatos circulavam, chamando a atenção da população sobre um provável ataque ao Recife pelas milícias de Goiana. Tais rumores concorriam para a desertificação das ruas e o fechamento repentino das casas de negócios. Patrulhas vasculhavam as ruas e quase sempre eram revezadas por tropas reais devido às freqüentes deserções de soldados que se baldeavam para as fileiras dos exércitos de Goiana. Parte das estradas que davam acesso ao Recife foi bloqueada ora pelos rebeldes, ora pelas tropas de Luís do Rego. Em uma dessas cavalgadas, presenciou Maria Graham cavaleiros

63 "Pernambuco no movimento da independencia", en Correspondência oficial do Governo da Província, entre agosto e outubro de 1821 (Recife: Governo do Estado de Pernambuco; Secretaria Estadual de Cultura, 1973), 574 -576.

${ }^{64}$ AHU (Lisboa), ACL_CU, 015, caja 284, doc. 19388.

${ }^{65}$ Maria Graham, "Diário de uma viagem ao Brasil", en Uma inglesa em Pernambuco nos começos do século XIX, ed. Waldemar Valente (Recife: Imprensa Oficial, 1957), 96 y 102. 
empunhando bandeiras brancas, alguns deles portando trajes militares e outros à paisana. Tratava-se de deputados paraibanos que vieram propor ao governador pernambucano, após conversa com as lideranças do governo de Goiana, solução para o impasse político criado na província.

Estando o Recife e Olinda em estado de tensão, Luís do Rego recebeu do Rio de Janeiro mensagem, datada de 21 de agosto de 1821 , de que o príncipe regente d. Pedro determinava que o governador instituísse em Pernambuco uma junta provisória para governar a província segundo as leis e bases da Constituição portuguesa, com subordinação e obediência a ele como regente do reino do Brasil $^{66}$. Ao tomar conhecimento de tais determinações, Luís do Rego prontamente mandou a Câmara do Recife executar as ordens do Rio, o que não foi feito, mesmo havendo convocação para o dia 22, em virtude das agitações das ruas, que se encontravam tomadas pelas forças das duas juntas de governo beligerante. $\mathrm{O}$ governador tentou resistir às determinações do Rio de Janeiro, chegando a tentar acordo de paz com o governo de Goiana, solicitando que elementos desse governo se unissem ao seu, porque, segundo suas convicções, seu governo era constitucional $^{67}$. Em resposta, a junta de Goiana, em 6 de setembro de 1821, dizia desconhecer a legitimidade daquele governo, uma vez que ele foi construído sob "tumulto, pancadas [e] prisões", por isso aquela junta não aceitava "o honroso convite" e não desejava "dilatar por muito tempo" o governo por entender que ele:

foi instalado com a condição de durar somente até que se instale uma junta provisional na capital da província pelos cidadãos de todas as classes em plena liberdade ${ }^{68}$.

Após alguns dias, reuniram-se os representantes dos dois governos na povoação de Beberibe, onde assinaram um armistício em 5 de outubro de 1821, o qual determinava que Luís do Rego e seu conselho ficariam no governo, circunscrevendo seu poder apenas à vila do Recife e à cidade de Olinda e seus termos, enquanto a junta de Goiana continuaria responsável pela administração das vilas do interior até a decisão final das cortes e do rei, que deveriam deliberar quais das duas juntas deveria governar toda a província. Tal acordo entraria para a história de Pernambuco com o nome de Convenção de Beberibe e foi ratificado pelo governador e seu conselho em 9 de outubro de 1821. Alguns focos de resistência foram registrados no interior em solidariedade a Luís do Rego Barreto ${ }^{69}$. Na prática, a Convenção de Beberibe antecipava o Decreto das Cortes, de $1^{\circ}$ de setembro de 1821, e a Carta Régia, de 2 de setembro de 1821, que ordenavam a

\footnotetext{
${ }^{66}$ APEJE (Recife), OR, 41, fol. 136.

${ }^{67}$ Barreto, Memória justificativa, 104.

${ }^{68}$ Ibídem, 107.

69 "Pernambuco no movimento", 98.
} 
criação, em Pernambuco, de uma junta provisória de governo, a qual deveria ser eleita pelos eleitores das comarcas pernambucanas.

A eleição dos membros da nova junta provisional de Pernambuco foi marcada para o dia 26 de outubro de 1821. A Câmara olindense, reunida no dia anterior, cientificada de que alguns movimentos de manifestação contrários às eleições estavam sendo urdidos no Recife, solicitou a Luís do Rego que em nome do soberano Congresso e do rei recolhesse as tropas aos quartéis e tomasse medidas necessárias para evitar convulsões públicas. Em resposta, Luís do Rego negava a existência de tais rumores e dizia que se não estivesse "persuadido de que Vossas Senhorias obravam de boa-fé, creria que mais um falso suposto se lançava mão para deitar peçonha no que é em si mesmo inocente" ${ }^{\text {,70 }}$. O colégio eleitoral pernambucano elegeu, para a nova junta de governo, Gervásio Pires Ferreira (presidente), padre Laurentino Antônio Moreira de Carvalho (secretário) e, para membros, o cônego Manuel Inácio de Carvalho, o tenente-coronel Antônio José Vitoriano Borges da Fonseca, Felipe Néri Ferreira, Joaquim José de Miranda e Bento José da Costa.

Longe das garras de Luís do Rego Barreto, elementos do povo passaram a cantarolar modinhas, ora ressaltando os benefícios que a futura Constituição ia trazer, ora enxovalhando o ex-governador, demonstrando, no dizer de Arlette Farge $^{71}$, que "la rue est un acteur social": "Luís do Rego foi guerreiro/ Sete campanhas venceu, / Mas na oitava de Goiana/ Luís do Rego esmoreceu". Depois de uma perseguição intensa vivida pela população pernambucana, de 1817 a 1821 , datas de posse e saída de Luís do Rego, estando os ânimos agitados pela demissão deste, veio à tona outra modinha, que não deixou de fora a mulher do exgovernador: "A mulher de Luís do Rego/ Manducava só galinha,/ Ainda não era princesa/ Já queria ser rainha”.

Se a demissão do governador agradou aos liberais, havendo dias consecutivos de festa no Recife, o mesmo não foi compactuado pelos absolutistas. O recifense percebeu esse desespero e assim cantarolava pelos logradouros públicos: "Luís do Rego foi-se embora/ Sem dizer nada a ninguém,/ Os corcundas estão dizendo/ Luís do Rego logo vem" ${ }^{, 72}$. Tudo isso, no dizer de Farge ${ }^{73}$, demonstra que "l'opinion n'est pas une vague qui grossit pour s'abattre sur une plage lisse", cada circunstância tem suas especificidades, merecendo investigações. Aqui, procuramos investigar as instabilidades políticas com um olhar sobre as ruas por

\footnotetext{
${ }^{70}$ Barreto, Memória justificativa, 140.

${ }^{71}$ Farge, Dire et mal dire, 23.

${ }^{72}$ Amaral, Escavações, 96.

${ }^{73}$ Farge, Dire et mal dire, 63.
} 
ocasião dos últimos anos da monarquia absoluta que antecipam a fundação do Estado Nacional que ocorreria em 7 de setembro de 1822.

As tramas de 1820 e 1821 mostram que mesmo impedidas de comentar ou utilizar palavras que identificavam o movimento vintista, as pessoas falavam, burlando tais interdições. E nesse contexto a palavra verbal fugiu do controle dos mantenedores do Antigo Regime, porque, como explica Michel de Certeau "la toma de la palabra tiene la forma de un rechazo; es una protesta" ${ }^{74}$. Ensina Habermas que quando povo comentava pelas ruas ou até mesmo em casa o que via e ouvia, não se encontrava "completamente excluído", tendo em vista que falava ${ }^{75}$. Naqueles tumultos, foi comum, nas diversas manifestações de rua, ouvir gritos dando vivas ao rei, às cortes e à Constituição, por entenderem que somente a Constituição que estava sendo elaborada em Portugal ia melhorar a sorte das pessoas e salvar o reino da corrupção.

\section{Bibliografía}

\section{Fuentes primarias}

Arquivo Nacional do Rio de Janeiro, Rio de Janeiro, Brasil.

Arquivo Público Jordão Emerenciano, Recife, Brasil.

Arquivo Histórico Ultramarino, Lisboa, Portugal.

Biblioteca Nacional do Rio de Janeiro, Rio de Janeiro, Brasil.

"Pernambuco no movimento da independencia". En Correspondência oficial do Governo da Província, entre agosto e outubro de 1821. Recife: Governo do Estado de Pernambuco, 1973.

\section{Fuentes secundarias}

Amaral, Francisco Pacífico do. Escavações: fatos da história de Pernambuco. $2^{\text {a }}$ ed. Recife: Arquivo Público Estadual, 1974.

Barreto, Luís do Rego. Memória justificativa sobre a conducta do marechal de campo Luiz do Rego Barreto durante o tempo em que foi governador de

74 Michel de Certeau, La toma de la palabra y otros escritos políticos (México: Universidad Iberoamericana; Instituto Tecnológico y de Estudios Superiores de Occidente, 1995), 40.

75 Jürgen Habermas, Mudança estrutural da esfera pública: investigações quanto a uma categoria da sociedade burguesa, 2 ed. (Rio de Janeiro: Tempo Brasileiro, 2003), 23. 
Pernambuco, e presidente da junta constitucional do governo da mesma província. Lisboa: Typographia de Desiderio Marques Leão, 1822.

Berbel, Márcia Regina. A nação como artefato: deputados do Brasil nas cortes portuguesas (1821-1822). São Paulo: Hucitec; Fapesp, 1999.

Pátria e patriotismo em Pernambuco. En Brasil: formação do estado e da nação, ed. Istvan Jancsó. São Paulo: Hucitec; Unijuí; Fapesp, 2003.

Bernardes, Denis Antônio de Mendonça. $O$ patriotismo constitucional: Pernambuco, 1820-1822. Tesis doctoral, Universidade de São Paulo, São Paulo, 2001.

Cabral, Flavio José Gomes. Paraíso terreal: a rebelião sebastianista na serra do Rodeador. Pernambuco -1820. São Paulo: Annablume, 2004.

. "Uma sedição abortada em 1820: contestação e política repressiva em Pernambuco as vésperas da independência". Anais do XXIII Simpósio Nacional de História: História: guerra e paz. Londrina: ANPUH, CDROM, 2005.

"Cartas Pernambucanas de Luís do Rego Barreto". Revista do Instituto Arqueológico, Histórico e Geográfico Pernambucano (Recife), 52 (1979).

Cavalcanti, Zélia. "O processo de independência na Bahia". En 1822: dimensões, ed. Carlos Guilherme Mota. São Paulo: Perspectiva, 1986.

Carvalho, José Murilo de. A construção da ordem: a elite política imperial. Rio de Janeiro: Campus, 1980.

Carvalho, Marcus J. M. de. "Os militares e a revolução de 1817 em Pernambuco". Anais da XVII Reunião da Sociedade Brasileira de Pesquisa Histórica. São Paulo: SBPH, 1997.

"Cavalcantis e cavalgados: a formação das alianças políticas em Pernambuco, 1817-1824”. Revista Brasileira de História (São Paulo), 18, núm. 36 (1998): 331-365.

Liberdade: rotinas e rupturas do escravismo no Recife, 1822-1850. Recife: UFPE, 1998. 
Certeau, Michel de. La toma de la palabra y otros escritos políticos. México: Universidad Iberoamericana; Instituto Tecnológico y de Estudios Superiores de Occidente, 1995.

Costa, Emília Viotti da. "Introdução ao estudo da emancipação política do Brasil". En Brasil em perspectiva, ed. Carlos Guilherme Mota. 12a ed. São Paulo: Difel, 1981.

Costa, Pereira da. Anais pernambucanos, 1795-1817. Recife: Arquivo Público Estadual, 1958.

Anais pernambucanos, 1818-1823. Coleção Pernambucana. $2^{\mathrm{a}}$ ed. Vol. 8. Recife: Fundarpe, 1984.

Darnton, Robert. Os best-sellers proibidos da França pré-revolucionária. São Paulo: Companhia das Letras, 1998.

"Uma precoce sociedade da informação". Varia História (Belo Horizonte), 25 (julio 2001): 9-51.

Farge, Arlette. Dire et mal dire: l'opinion publique au XVIII e siècle. Paris: Seuil, 1992.

Graham, Maria. "Diário de uma viagem ao Brasil". En Uma inglesa em Pernambuco nos começos do século XIX, ed. Waldemar Valente. Recife: Imprensa Oficial, 1957.

Habermas, Jürgen. Mudança estrutural da esfera pública: investigações quanto a uma categoria da sociedade burguesa. 2 ed. Rio de Janeiro: Tempo Brasileiro, 2003.

Jancsó, István. “A sedução da liberdade”. En História da vida privada na América Portuguesa, ed. Laura de Mello e Souza. $4^{\text {a }}$ ed. Vol. 1: 388-437. São Paulo: Companhia das Letras, 1998.

Jancsó, István y João Paulo G. Pimenta. "Peças de um mosaico (ou apontamento para o estudo da emergência da identidade nacional brasileira)". En Viagem Incompleta. A experiência brasileira (1500-2000). Formação: histórica, ed. Carlos Guilherme Mota. $2^{\text {a }}$ ed. São Paulo: Senac, 2000.

Koster, Henry. Viagens ao nordeste do Brasil. 11 a ed. Vol. 1. Recife: Fundação Joaquim Nabuco; Massangana, 2002. 
Leite, Glacyra Lazzari. Pernambuco 1817: estruturas e comportamentos sociais. Recife: Fundação Joaquim Nabuco; Massangana, 1998.

Lyra, Maria de Lourdes Viana. A utopia do poderoso império: Portugal e Brasil: bastidores da política, 1798-1822. Rio de Janeiro: Sette Letras, 1994.

Maxwell, Kenneth. "Por que o Brasil foi diferente? O contexto da independência. Formação: histórias". En Viagem incompleta. A experiência brasileira (1500-2000). Formação: histórias, ed. Carlos Guilherme Mota. 2 ed. São Paulo: Senac, 2000.

Maxwell, Kenneth y Maria Beatriz Nizza da Silva. "A política". En $O$ império luso-brasileiro-1750-1822, ed. Maria Beatriz Nizza da Silva. Vol. 8. Lisboa: Estampa, 1986.

Mello, Evaldo Cabral de. A outra independência: o federalismo pernambucano de 1817 a 1824. São Paulo: Ed. 34, 2004.

Mota, Carlos Guilherme. Nordeste 1817: estruturas e argumentos. São Paulo: Perspectiva, 1972. . Idéia de revolução no Brasil, 1789-1801. $4^{\mathrm{a}}$ ed. São Paulo: Ática, 1996.

Neves, Guilherme Ferreira das. "Del imperio lusobrasileño al imperio del Brasil (1789-1822)". En Inventando la nación Iberoamérica, siglo XIX, eds. Antonio Annino y François-Xavier Guerra. México: Fondo de Cultura Económica, 2003.

Neves, Lúcia Maria Bastos Pereira das. "Liberalismo político no Brasil: idéias, representações e práticas, 1820-1823". En O liberalismo no Brasil imperial: origens, conceitos e práticas, eds. Lúcia Maria Paschoal Guimarães y Maria Emília Prado. Rio de Janeiro: Revan; UERJ, 2001.

Corcundas e constitucionais: a cultura política da Independência (1820-1822). Rio de Janeiro: Revan; Faperj, 2003.

Porto, Costa. Os tempos de Gervásio Pires. Recife: Governo do estado de Pernambuco, 1978.

Pereira, Miriam Halpern. Das revoluções liberais ao Estado Novo. Lisboa: Presença, 1993. 
Proença, Maria Cândida. A independência do Brasil: relações externas portuguesas, 1808-1825. Lisboa: Livros Horizonte, 1987.

Ribeiro, Gladys Sabina. A liberdade em construção: identidade nacional e conflitos antilusitanos no primeiro reinado. Rio de Janeiro: Relume Dumará, 2002.

Revista do instituto arqueológico, histórico e geográfico pernambucano (Recife), 13, num. 73 (1908).

Rodrigues, José Honório. Independência: revolução e contra-revolução. Vol. 1. Rio de Janeiro: Livraria Francisco Alves, 1975.

Tomás, Manuel Fernandes. A revolução de 1820. Coleção Universitária núm. 2. $2^{\text {a }}$ ed. Lisboa: Caminho, 1982.

Silva, Luiz Geraldo. A faina, a festa e o rito: uma etnografia histórica sobre as gentes do mar (sécs. XVII ao XIX). Campinas: Papirus, 2001.

Souza, Iara Lis Franco. Pátria coroada: o Brasil como corpo político autônomo, 1780-1831. Sao Paulo: UNESP, 1999.

Souza, Maria Aparecida Silva de. "Nação, pátria e império: as câmaras municipais baianas e a independência". En As múltiplas dimensões da política e da narrativa, eds. Teresa Malatian, Marisa Saenz Leme, Ivan Aparecido Manoel, 65-75. Franca y São Paulo: UNESP/ Olho d’Água, 2004.

Souza Filho, Argemiro Ribeiro de. "As juntas governativas e a independência: 'multiplicidade de poder' na Bahia”. En As múltiplas dimensões da política e da narrativa, eds. Teresa Malatian, Marisa Saenz Leme, Ivan Aparecido Manoel, 51-63. Franca y São Paulo: UNESP/ Olho d’Água, 2004.

Vargues, Isabel Nobre. A aprendizagem da cidadania em Portugal - 1820-1823. Coimbra: Minerva, 1997.

Vargues, Isabel Nobre y Maria Manuela Tavares Riveiro. "Estruturas políticas: parlamentos, eleições, partidos políticos e maçonarias". En O liberalismo (1807-1890), eds. Luís Reis Torgal y João Lourenço Roque. Lisboa: Estampa, 1998.

Valentim, Alexandre. Os sentidos do império: questão nacional e questão colonial na crise do antigo regime português. Porto: Aforamento, 1993. 
Fecha de recepción: 10 de diciembre de 2005.

Fecha de aprobación: 14 de junio de 2006. 